\title{
QUANTIFYING SPRAY DEPOSITION FROM A UAV CONFIGURED FOR SPOT SPRAY APPLICATIONS TO INDIVIDUAL PLANTS
}

\author{
B. Richardson, C. Rolando, M. Kimberley
}

\section{HighLIGHTS}

- Spot spraying is a method for applying pesticides to individual tree crowns.

- A new method is presented to quantify and analyze the two-dimensional spot spray deposit pattern produced by a UAV.

- A bivariate normal distribution provided a good fit to the observed deposition data for all treatments.

- Model parameters effectively described the shape of the ground deposits.

\begin{abstract}
The purpose of this study was to develop a method for quantifying and analyzing the two-dimensional spray deposit pattern produced from a UAV spot spraying system for applying pesticides to individual plants with crown diameters in the range of 1 to $2 \mathrm{~m}$. An XAG P20 UAV was flown over the center of a sampling grid, and spray deposits from three droplet size treatments, with nominal volume median diameters (VMDs) of 335, 430, and $1150 \mu \mathrm{m}$, were measured using horizontal steel plate collectors placed on blocks on the ground. A colorimetric tracer in the spray mix was used to quantify spray deposition. The positioning accuracy of the UAV was excellent, but the droplet sizes produced were much larger than expected. A bivariate normal distribution provided a good fit to the observed deposition data for all treatments. Model parameters effectively described the shape of the ground deposits. Displacement of the deposit distribution center was in a downwind direction. While there were no statistically significant effects of wind speed on the shape or degree of displacement of the center of mass of the observed ground deposit pattern, this was probably a result of the low wind speeds during the study, which were often close to or below the lower sensitivity threshold of the anemometer used. The actual spray coverage on a $2 \mathrm{~m}$ tall artificial tree target of 1 or $2 \mathrm{~m}$ diameter placed in the center of the plot was consistent across the range of droplet sizes and operating conditions tested. Nevertheless, it is hypothesized that targeting could be further improved if the UAV was slightly offset in an upwind direction and, conceptually, the degree of this displacement would increase as wind speed increased. A sampling grid spacing of $1.0 \mathrm{~m}$ would have produced results similar to the $0.5 \mathrm{~m}$ spacing actually used.
\end{abstract}

Keywords. Aerial spraying, Pesticides, Spot spraying, Spray deposition, UAV, Unmanned aerial vehicle.

U sing multi-rotor unmanned aerial vehicles (UAVs) for pesticide spray application offers several niche opportunities due to their potential for improved precision compared with alternatives (Huang et al., 2009; Giles and Billing, 2015). While a number of studies have been published on the spray application efficiency of UAVs configured for conventional swath spraying (Faiçal et al., 2014; Xue et al., 2014; Tang et al., 2017; Wang et al. 2017, 2019), there is little information on

\footnotetext{
(c) $(1) \$$ The authors have paid for open access for this article. This NonCommercial-NoDerivatives 4.0 International License https://creative commons.org/licenses/by-nc-nd/4.0/

Submitted for review in October 2019 as manuscript number MS 13724; approved for publication as a Research Article by the Machinery Systems Community of ASABE in April 2020.

The authors are Brian Richardson, Principal Scientist, Carol A. Rolando, Senior Scientist, and Mark O. Kimberley, Senior Biometrician, New Zealand Forest Research Institute (Scion), Rotorua, New Zealand. Corresponding author: Brian Richardson, Scion, 49 Sala St., Private Bag 3020, Rotorua 3046, New Zealand, phone: '+64-7-343-5516; e-mail: brian.richardson@scionresearch.com.
}

the targeting efficiency of UAVs configured for spot treatment of individual plants. There are several situations in which individual-plant treatment is desirable. For example, in New Zealand's planted forests, weeds are often controlled around individual crop trees using hand-held applicators that deliver a circular dose of herbicide around each target tree (Davenhill et al., 1991; Richardson et al., 2019). Helicopters have also been used for individual tree treatment in pest eradication operations in urban or suburban environments (Strand et al., 2014) and to control individual, dispersed, invasive "wilding" conifers using herbicides (Gous et al., 2014). Introduced conifer species are spreading from planted forests, shelter belts, and amenity plantings into a variety of habitats over large areas of New Zealand where they are not wanted (Ledgard, 2001). There is a national program to control wilding conifers and interest in evaluating whether UAVs offer a more cost-effective and safer platform for aerial spot spraying of isolated conifers than existing helicopter methods. However, there is little information on the suitability of UAV spraying systems for this type of application.

The main aim of this study was to develop a method for characterizing the spray deposition pattern produced with a 
UAV configured for spot spraying and for quantifying the ability of the UAV to effectively target individual trees with crown diameters in the range of 1 to $2 \mathrm{~m}$. For conventional aerial spraying, uniformity of deposition is normally described by measuring the swath pattern, where spray deposits are sampled along a line perpendicular to the direction of flight (Parkin and Wyatt, 1982; Richardson et al., 2004). However, spot treatment requires characterization of the deposit pattern in two dimensions, which can require intensive and costly sampling protocols. Consequently, the specific objectives of this study were to:

- Develop a method for efficiently characterizing the two-dimensional spray deposit pattern from an aerial spot spraying treatment.

- Evaluate the targeting efficiency of the XAG P20 UAV spot spraying system.

\section{MATERIALS AND METHODS TRIAL LOCATION, SPRAYING SYSTEM, AND TREATMENTS}

The trial was undertaken on the North Island of New Zealand $\left(38.184^{\circ} \mathrm{S}, 176.236^{\circ} \mathrm{E}\right)$ at a flat, open site with a uniform, hard pumice surface at an elevation of $420 \mathrm{~m}$ above sea level. All spot applications were made with an XAG P20 aircraft (XAG Ltd., Guangzhou, China) on 14 November 2018. The P20 is a quadcopter (fig. 1) with a $25 \mathrm{~kg}$ maximum take-off weight, $10 \mathrm{~kg}$ load capacity and, among other features, GNSS RTK (global navigation satellite system, realtime kinetic) high-precision navigation. The spraying system uses four spinning disc rotary atomizers, one located under each rotor. Droplet size is altered by changing the disc rpm and/or flow rate.

The P20 was pre-programmed to deliver a spot treatment by releasing spray over the central point in each sample plot. Prior to each application, the aircraft flew from the take-off and landing area, avoiding passing over any of the other sampling plots, to the required position over the center of the target grid. These central points were marked prior to spraying using the hand-held XAG GPS system and RTK base station. The P20 has a novel spot application method; it positions itself over the programmed target and then rotates on its central axis at approximately $6 \mathrm{rpm}$ for the time needed to deliver the target application volume. For this experiment, there were three droplet size treatments, each replicated four times, comprising nominal volume median diameters (VMDs) of approximately 335, 430, or $1150 \mu \mathrm{m}$. These droplet sizes were respectively associated with spinning disc speeds of 3000, 2000, and $1000 \mathrm{rpm}$ and a flow rate of $0.3 \mathrm{~L}$ $\mathrm{min}^{-1}$ onto each disc (XAG, personal communication). Spray release height was nominally $3.0 \mathrm{~m}$ above the ground, and total spray flow rate was nominally $1.2 \mathrm{~L} \mathrm{~min}^{-1}$.

Actual spray release heights during treatment were taken from the aircraft GPS log after spraying. No specific application rate (based on the amount of spray released per unit ground area) was targeted because defining the area over which the spray is distributed, a key determinant of application rate, was one of the objectives of the work. However, if a spot size of $3 \mathrm{~m}$ diameter was assumed, then the nominal application rate would be equivalent to about $250 \mathrm{~L} \mathrm{ha}^{-1}$. While calibration of the P20 demonstrated consistency in output, the UAV does not track and log the actual amount of spray released for each application, so there was no independent verification of this quantity other than the recorded spray duration from the aircraft log file and the nominal flow rate. Manual measurements were also made of the duration of spraying and, for a subset of four plots, overhead video recordings from a second UAV (Phantom, DJI, Shenzhen, China) provided a second estimate of spray duration. The total amount of spray released was estimated from the nominal flow rate and observed spraying duration.

\section{SPRAY DEPOSIT SAMPLING SCHEME AND MEASUREMENT}

To apply each treatment, spray was released from the P20 above the central point of a $7 \mathrm{~m} \times 7 \mathrm{~m}$ sampling area in which spray deposits were collected on horizontal, stainless steel plates $(76 \mathrm{~mm} \times 152 \mathrm{~mm} \times 1 \mathrm{~mm}$ ) placed on $25 \mathrm{~mm}$ high wooden blocks on the ground. The sampling area consisted of an inner $5 \mathrm{~m} \times 5 \mathrm{~m}$ grid with spray collectors at $0.5 \mathrm{~m}$ intervals (fig. 2). This inner sampling area was extended to

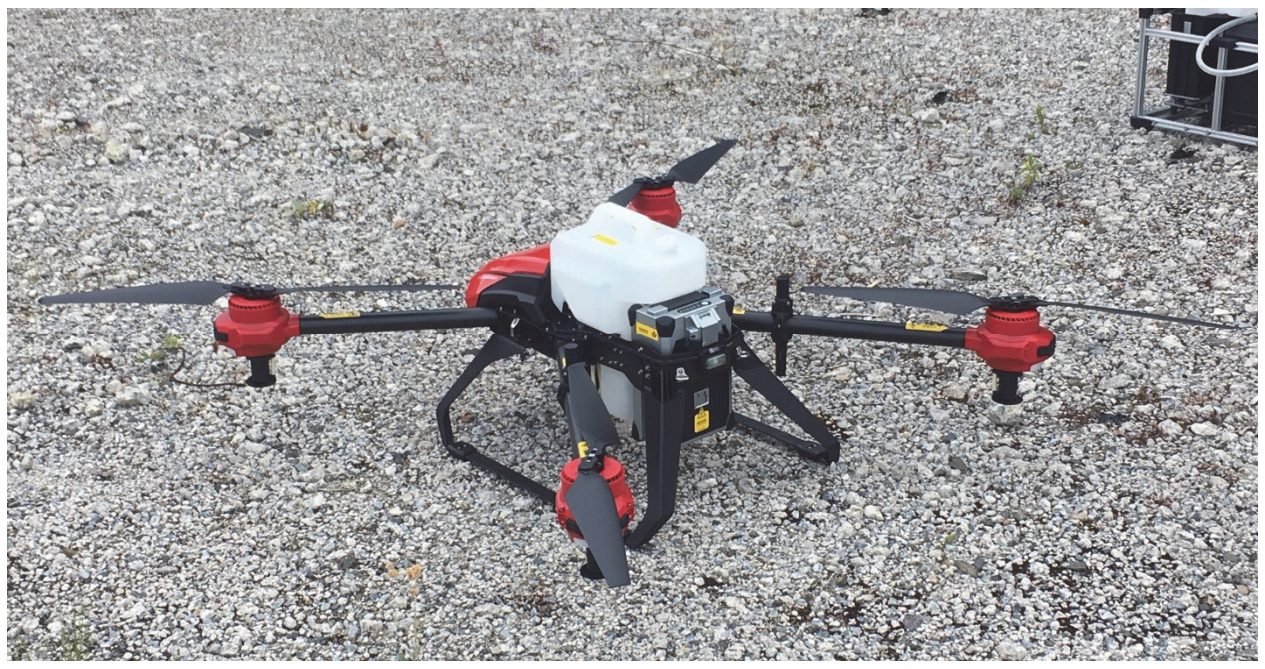

Figure 1. XAG P20 with a spinning disc atomizer under each of the four rotors. 


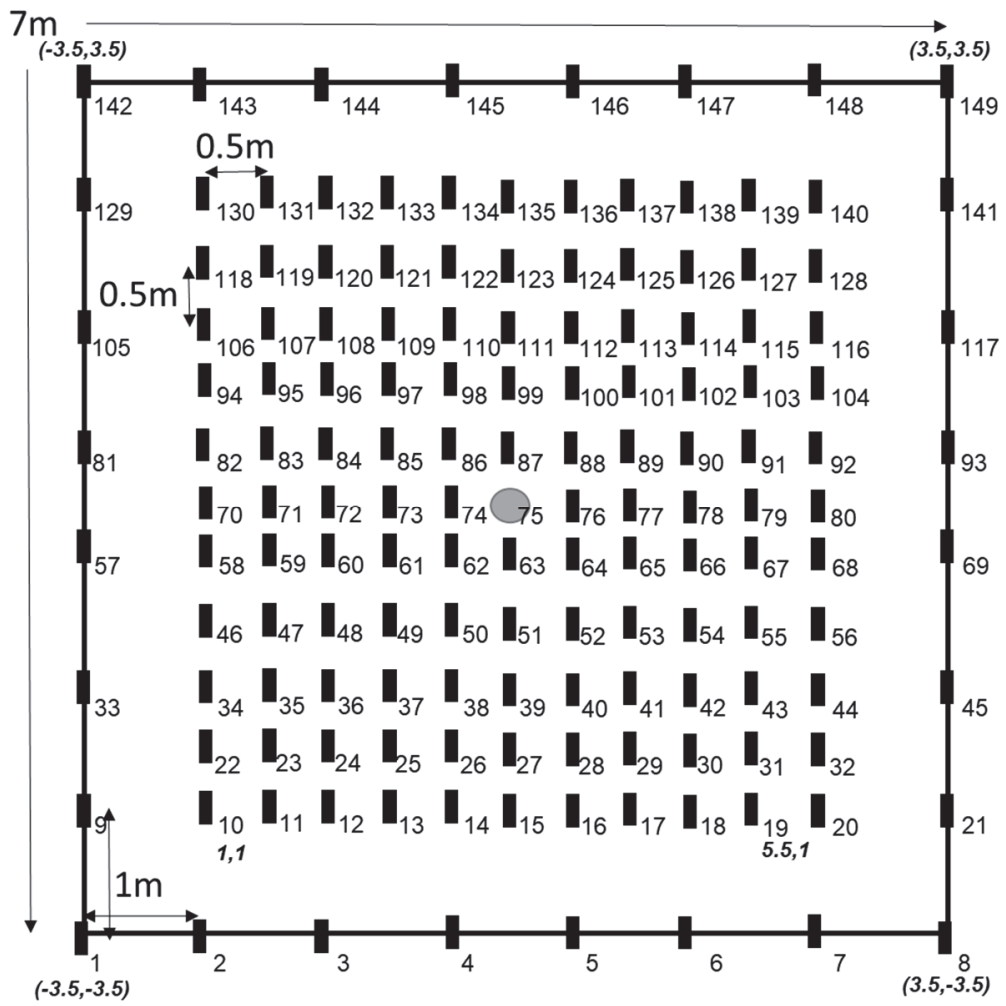

Figure 2. Sampling grid layout with unique numbers and coordinates for each of 149 steel plate spray deposit collectors. Spray was released with the UAV hovering over sample $75(x=0, y=0)$.

$7 \mathrm{~m} \times 7 \mathrm{~m}$ by adding a set of sampling points extending $1 \mathrm{~m}$ on each side of the inner square but at a $1 \mathrm{~m}$ spacing rather than $0.5 \mathrm{~m}$, giving an additional 28 sampling points and an overall total of 149 . The reduced sampling intensity at the grid perimeter was simply for logistical purposes and to reduce the associated manpower required to deal with the large number of samples. A total of 16 plots were established and surveyed (Geo7x, Trimble Geospatial, Sunnyvale, Cal.), with adjacent plots separated by a $7 \mathrm{~m}$ buffer. Each sample point was numbered to provide an identifier for location coded in meters as $(x, y)$, with the central point (sample 75) fixed as the origin $(x=0, y=0)$.

All of the plots, except one replicate of the $1150 \mu \mathrm{m}$ droplet treatment, also included a second set of steel plates configured to represent an artificial tree comprising a $2 \mathrm{~m}$ high alloy pole located at the center of the grid with $2 \mathrm{~m}$ diameter cross-arms at heights of $1 \mathrm{~m}$ and $2 \mathrm{~m}$ above the ground (fig. 3 ). The arms were oriented to cardinal points, and steel plate collectors were placed horizontally at the ends of the arms (the outer position) and $0.5 \mathrm{~m}$ from the arm center (the inner position). In total, there were 16 plates ( 8 at each height) on each artificial tree.

The spray mix applied was water containing $0.01 \mathrm{~kg} \mathrm{~L}^{-1}$ tartrazine, a light-stable colorimetric tracer (Hawkins Watts Ltd., Auckland, New Zealand). Previous work has shown that tartrazine can be recovered with $100 \%$ efficiency from steel plates (Richardson and Thistle, 2006). After each spray application, the steel plates were allowed to dry and subsequently were individually placed into labeled plastic bags. Spray deposition was quantified using standard colorimetric techniques (Richardson et al., 1989), with the light absorbance of the sample measured at $\lambda_{\max }=427 \mathrm{~nm}$ using a spectrophotometer (T70 UV/VIS, PG Instruments Ltd., Leicester, U.K.). Deposition was calculated by reference to the tracer concentration in tank samples taken periodically throughout the trial.

Finally, on two plots per treatment, a continuous line of cast-coated cards, with a width of $10 \mathrm{~cm}$, was placed from the plot center to the downwind sampling extent. After spraying, a sample of approximately 5,000 to 10,000 droplet stain diameters per replicate were measured using standard image analysis techniques. Stain diameters were converted to true droplet diameters using a spread factor (Matthews, 2008) based on the measured relationship between true droplet diameter and stain diameter on the same batch of cards used in the field study. Droplets of differing sizes were generated using spinning discs (Micromiser 5 and 10 and Herbi, Micron Sprayers Ltd., Bromyard, U.K.) and with a microapplicator (Burkard Manufacturing Co. Ltd., Rickmansworth, U.K.). True droplet diameters were estimated using magnesium oxide coated slides for droplets with diameters less than about $200 \mu \mathrm{m}$ (Matthews, 2008) and with standard colorimetric techniques for larger sizes, i.e., the true droplet diameter produced from screened spinning discs or a microapplicator was quantified by estimating the droplet volume using colorimetry (as described above) and compared with the stain diameter on cards. 


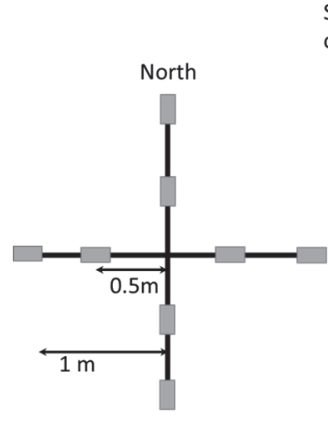

Top view

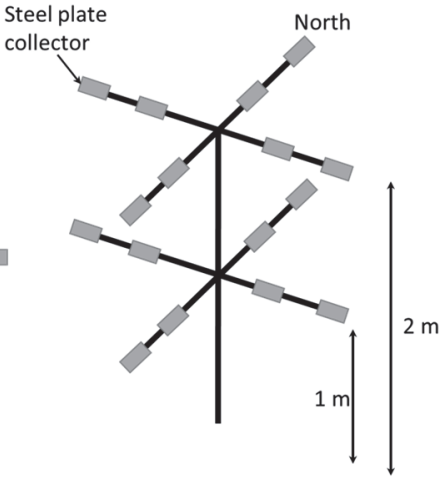

Side view
Figure 3. Top and side views of artificial trees located at the center of the sampling grids for collecting spray deposits.

\section{Meteorology AND AnCILlary MeAsurements}

Wind speed and direction (05103 Wind Monitor, R.M. Young, Traverse City, Mich.) and temperature and humidity (EE181 temperature and humidity probe, Campbell Scientific, Logan, Utah) were measured at $3 \mathrm{~m}$ above ground level. A data logger (CR1000, Campbell Scientific) provided $1 \mathrm{~s}$ averaged outputs for wind speed and direction, and $1 \mathrm{~min}$ averaged outputs for temperature and relative humidity.

\section{Data AnAlysis}

\section{Meteorological and Operational Variables}

Analysis of variance (ANOVA) was used to test for differences among treatments with respect to wind speed, air temperature, relative humidity, and release height during treatment application. The spread factor, describing the relationship between droplet stain diameters on the sampling cards and actual droplet diameters, was applied to the distribution of droplet stain sizes measured on sampling cards to estimate the VMD of deposited droplets.

\section{Ground Deposition}

Locations of all collectors were transformed to a true eastwest, north-south coordinate system. The distribution of spray deposition $\left(D, \mathrm{~L} \mathrm{~m}^{-2}\right)$ on each plate for each flight at ground level was modeled as a function of the location $(x, y)$ of the collector, with $x$ measured in meters in the east-west direction and $y$ in meters in the north-south direction, and the center of the grid location directly below the UAV, defined as $(x, y)=(0,0)$. The distribution was modeled based on the bivariate normal distribution:

$$
D=V /\left(2 \pi \sigma_{x} \sigma_{y} \sqrt{1-\rho^{2}}\right) \exp \left(-z /\left[2\left(1-\rho^{2}\right)\right]\right)
$$

where $z=\frac{\left(x-\mu_{x}\right)^{2}}{\sigma_{x}^{2}}-\frac{2 \rho\left(x-\mu_{x}\right)\left(y-\mu_{y}\right)}{\left(\sigma_{x} \sigma_{y}\right)}+\frac{\left(y-\mu_{y}\right)^{2}}{\sigma_{y}^{2}}$

This model has the following six parameters: $V$ is the total spray volume in liters summed over the distribution (note that because the integral over $x$ and $y$ of the unweighted bivariate distribution sums to one, the multiplier $V$ represents the total volume), $\mu_{x}$ and $\mu_{y}$ give the central location of the spray pattern in meters from the nominal center $(0,0)$, and $\sigma_{x}, \sigma_{y}$, and $\rho$ define the spread and shape of the distribution.

The region where spray deposition is greater than a specified threshold value $D_{t}$ forms an ellipse on the $(x, y)$ plane with the following equation:

$$
\frac{\left(x-\mu_{x}\right)^{2}}{\sigma_{x}^{2}}-\frac{2 \rho\left(x-\mu_{x}\right)\left(y-\mu_{y}\right)}{\left(\sigma_{x} \sigma_{y}\right)}+\frac{\left(y-\mu_{y}\right)^{2}}{\sigma_{y}^{2}}-K=0
$$

where $K=-2\left(1-\rho^{2}\right) \ln \left(2 \pi \sigma_{x} \sigma_{y} \sqrt{1-\rho^{2}} D_{t} / V\right)$

The size and shape of this ellipse is controlled by parameters $\sigma_{x}, \sigma_{y}$, and $\rho$. For example, when $\sigma_{x}=\sigma_{y}$ and $\rho=0$, the deposition area is a circle. When $\rho$ is positive, the orientation of the longer axis of the ellipse is inclined in a positive direction, and when $\rho$ is negative it is inclined in a negative direction. The ratio of the length of the minor axis to the major axis of the ellipse $(R)$ can be calculated from these parameters as follows:

$$
\begin{aligned}
R=\left[\left(\frac{\sigma_{y}}{\sigma_{x}}+\frac{\sigma_{x}}{\sigma_{y}}-\sqrt{\left(\frac{\sigma_{y}}{\sigma_{x}}-\frac{\sigma_{x}}{\sigma_{y}}\right)^{2}+4 \rho^{2}}\right)\right. \\
\left.\div\left(\frac{\sigma_{y}}{\sigma_{x}}+\frac{\sigma_{x}}{\sigma_{y}}+\sqrt{\left(\frac{\sigma_{y}}{\sigma_{x}}-\frac{\sigma_{x}}{\sigma_{y}}\right)^{2}+4 \rho^{2}}\right)\right]^{\frac{1}{2}}
\end{aligned}
$$

while the angle $(\phi)$ of the major axis of the ellipse measured clockwise from north is:

$$
\phi=\frac{\pi}{2}-\tan ^{-1}\left(\frac{\left(\frac{\sigma_{y}}{\sigma_{x}}-\frac{\sigma_{x}}{\sigma_{y}}+\sqrt{\left(\frac{\sigma_{y}}{\sigma_{x}}-\frac{\sigma_{x}}{\sigma_{y}}\right)^{2}+4 \rho^{2}}\right)}{2 \rho}\right)
$$

The area $\left(A, \mathrm{~m}^{2}\right)$ of the ellipse (i.e., the area with spray deposition greater than the threshold $D_{t}$ ) is:

$$
A=\pi K \sigma_{x} \sigma_{y} / \sqrt{1-\rho^{2}}
$$

The model (eq. 1) was fitted to the collection data using the nonlinear regression procedure (NLIN) in SAS version 9.4 , with $D$ as the dependent variable and the $(x, y)$ location of plates as independent variables. Separate estimates of the model parameters were obtained for each flight. From these, the angle $\left(\theta,{ }^{\circ}\right)$ and distance $(L, \mathrm{~m})$ of the center of the distribution from $(0,0)$ was calculated by converting $\left(\mu_{x}, \mu_{y}\right)$ to the polar coordinate system, and estimates of $R, \phi$, and $A$ were derived using equations 3, 4, and 5. Correlations (SAS CORR procedure; SAS, 1987) were used to test for relationships between distribution parameters. Regression analysis 
(SAS GLM procedure) was used to test for relationships between distribution parameters and operational variables, including wind speed and direction, and droplet diameter.

\section{Sampling Efficiency}

To determine whether a less intense sampling design could achieve similar results to those produced from the design described above, the above analysis was repeated, generating parameter values using reduced datasets, with plates spaced at 1 and $1.5 \mathrm{~m}$ intervals, reducing the number of sampling plates required by $57 \%$ and $76 \%$, respectively. Further analyses were also undertaken using only those plates located along the two diagonals and the cross centered at the central point.

\section{Artificial Trees}

The purpose of the artificial tree samples was to get an indication of the effectiveness of spray targeting on a threedimensional structure, given the expected horizontal displacement of the spray pattern from the point where spray emerges from the UAV atomizers close to the top of the sampling structure to the point where it is deposited on the ground. Following calculation of spray deposition for the 16 plates on each of the artificial trees, these data were analyzed in several ways. First, the ground-level model was tested against deposition data from the tree plates. This comparison was achieved by using the $x$ and $y$ coordinates of the plates to predict deposition using the ground-level model (eq. 1) fitted for each flight and plotting actual versus predicted deposition. Mean deposition was then calculated by flight and height $(0,1$, and $2 \mathrm{~m}$ above ground), with the ground-level $(0 \mathrm{~m})$ data taken from plates directly under the corresponding tree plates. An ANOVA was fitted using the SAS MIXED procedure to tests for differences in mean deposition by height above ground, with flight included as a random blocking effect in the model to account for differences between flights. Finally, spray coverage, i.e., the proportion of plates on a tree receiving a dose greater than thresholds of 25,50 , and $100 \mathrm{~L} \mathrm{ha}^{-1}$, was calculated for two cases: (1) the entire tree was included, representing a $2 \mathrm{~m}$ crown width (fig. 3), and (2) only the eight inner plates were evaluated, representing a smaller crown diameter of $1 \mathrm{~m}$. ANOVA was used to test for effects of droplet size and other derived covariates on spray coverage.

\section{RESULTS AND DISCUSSION}

\section{METEOROLOGICAL AND OPERATIONAL VARIABLES}

Wind speed was low, with treatment means ranging from 1.1 to $1.5 \mathrm{~m} \mathrm{~s}^{-1}$ (table 1), with no significant differences among treatments $(\mathrm{p}=0.54)$. Wind direction fluctuated throughout the experiment; however, while there were significant differences among treatments $(p<0.001)$, the vari- ance within each treatment was low (table 1). With these relatively low wind speeds, 4 of the 12 test flights were below the manufacturer's stated wind speed threshold $\left(1.0 \mathrm{~m} \mathrm{~s}^{-1}\right)$ for the 05103 Wind Monitor, and 5 of the 12 test flights were below the threshold for wind direction $\left(1.1 \mathrm{~m} \mathrm{~s}^{-1}\right)$. However, subsequent correlations between the Wind Monitor and a sonic anemometer (CSAT3B, Campbell Scientific) indicated that the Wind Monitor speed and direction data were relatively stable for wind speeds greater than $0.75 \mathrm{~m} \mathrm{~s}^{-1}$; hence, only one data point with a recorded wind speed of $0.5 \mathrm{~m} \mathrm{~s}^{-1}$ was omitted from subsequent analyses based on wind speed or direction.

While the temperature and humidity values were significantly different $(p<0.05)$ for each treatment, they were all in the moderate range for aerial spraying and, considering the relatively low spray release heights and large droplet spectra used, were unlikely to have had any effect on the observed deposition. There was no significant difference in release height among treatments $(\mathrm{p}=0.08)$, with an average release height of $3.5 \mathrm{~m}$ compared with the requested height of $3.0 \mathrm{~m}$.

Applying the spread factor of 0.55 (fig. $4 \mathrm{a}$ ) to the droplet stains measured on the card samples resulted in estimated VMDs that were substantially larger than the targeted nominal VMDs (fig. 4b), i.e., 660, 1153, and $2041 \mu \mathrm{m}$ versus 335,430 , and $1150 \mu \mathrm{m}$, respectively. These differences between nominal and measured VMDs are much larger than expected, even if the caveats of the measurement technique are considered, and probably reflect system calibration issues. Potential sampling biases include the low collection efficiency of small droplets on cards and the fact that individual droplets on cards closest to the center of the plots were not distinguishable due to the high coverage of spray. It is possible that sampling further out biased the measurements if there was a gradient of droplet size with distance from the center of the plot. It is also possible that the droplet spread on cards under field conditions was exaggerated by having a higher energy at impact in the field due to the higher velocities at impact resulting from both strong downwash velocities and greater release heights than in the laboratory. However, previous work has shown that for droplets up to $450 \mu \mathrm{m}$ true diameter, their impaction energy has much less influence on their spreading on cards than the nature of the card surface (Sundaram et al., 1991). Finally, it is possible that the VMD estimates on cards can be skewed if a high proportion of the small to medium droplet sizes are not captured on the sampling grid, implying a high degree of spray drift. However, this is unlikely, as the main spot swath deposition was clearly captured within the sampling grid, and it would be highly unusual for a droplet spectrum of this nature to have a driftable fraction that would create such large discrepancies in VMD comparisons.

Table 1. Mean and standard deviation (in parentheses) of meteorological variables and actual spray release height for each treatment.

\begin{tabular}{cccccc}
\hline $\begin{array}{c}\text { Treatment and } \\
\text { Droplet VMD }(\mu \mathrm{m})\end{array}$ & $\begin{array}{c}\text { Wind Speed } \\
\left(\mathrm{m} \mathrm{s}^{-1}\right)\end{array}$ & $\begin{array}{c}\text { Wind Direction } \\
\left({ }^{\circ}\right)\end{array}$ & $\begin{array}{c}\text { Temperature } \\
\left({ }^{\circ} \mathrm{C}\right)\end{array}$ & $\begin{array}{c}\text { Relative Humidity } \\
(\%)\end{array}$ & $\begin{array}{c}\text { Release Height } \\
(\mathrm{m})\end{array}$ \\
\hline Treatment 1 $(335)$ & $1.5(0.6)$ & $40.6(14.7)$ & $15.5(0.0)$ & $68.8(0.1)$ & $3.6(0.04)$ \\
Treatment 2 $(430)$ & $1.2(0.5)$ & $117.1(5.4)$ & $18.6(0.1)$ & $49.7(0.1)$ & $3.5(0.05)$ \\
Treatment 3 $(1150)$ & $1.1(0.5)$ & $57.7(18.9)$ & $15.4(0.0)$ & $67.6(0.2)$ & $3.6(0.08)$ \\
\hline
\end{tabular}




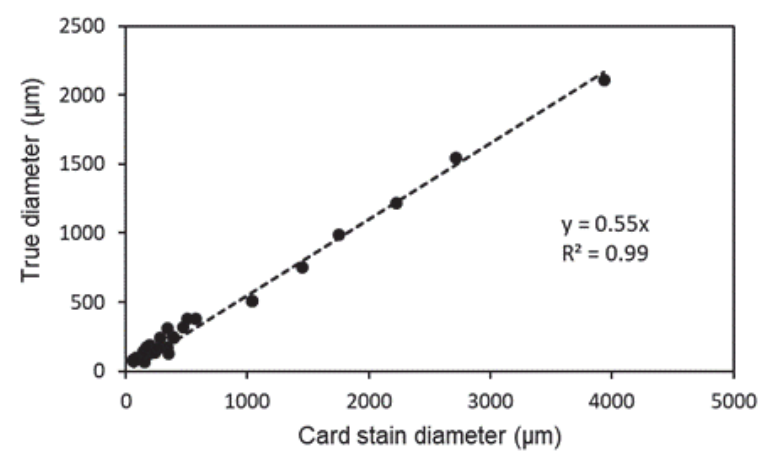

(a)

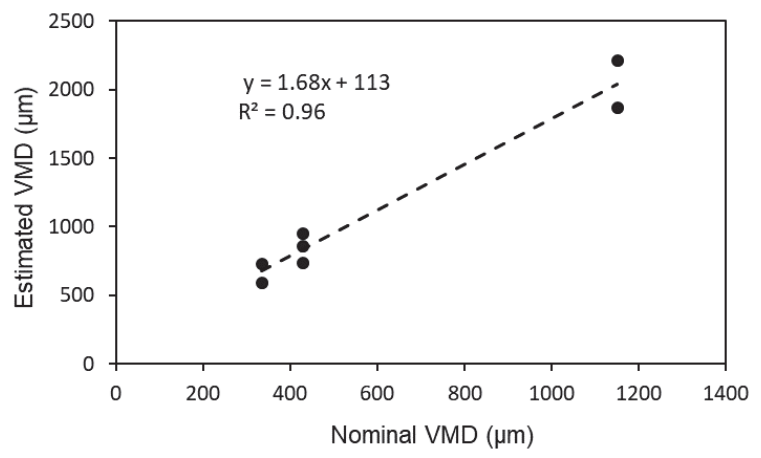

(b)

Figure 4. Measured relationship between (a) droplet stain diameters on sampling cards and true (airborne) droplet diameter and (b) resulting estimated volume median diameter (VMD) for applied treatments compared to nominal VMD.

\section{SPRAY DEPOSIT DISTRIBUTION}

In all cases, the ground sampling array captured the main extent of the spot deposition. The deposit distribution based on the bivariate normal distribution (eq. 1) provided a good fit for the measured deposit data across all flights (fig. 5). One replicate of the $430 \mu \mathrm{m}$ droplet treatment was omitted from the analysis because there was an observed problem with the spray output during the application.

Analysis of variance indicated that the only significant treatment (droplet size) effect on parameter estimates for the deposit distribution from fitting equation 1 (table 2) was on $\rho(p=0.005)$, indicating a slightly more elliptical deposit

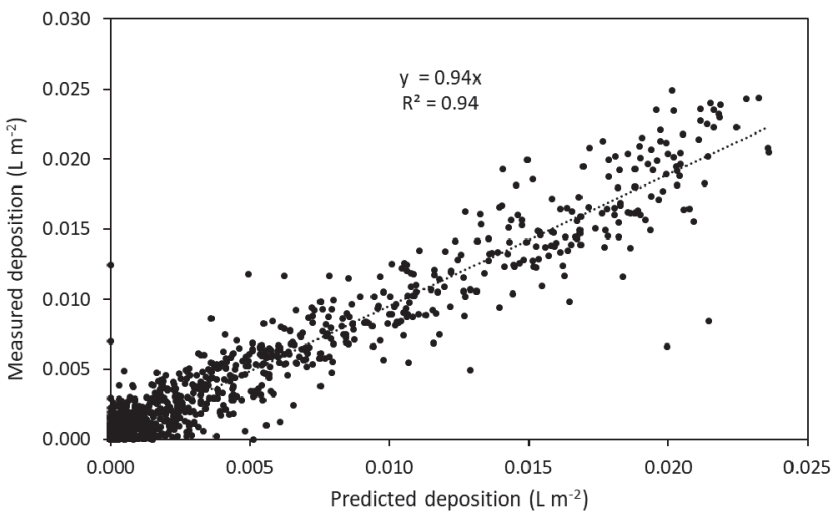

Figure 5. Measured deposition versus deposition predicted using equation 1 for ground-level plates across all flights. distribution with the smaller droplet size treatment. Given these minor differences between treatments, a typical deposit pattern for a spot treatment was generated (fig. 6) to highlight how this type of information can be used to calibrate spot treatment doses. From a practical perspective, spot treatment doses are generally specified as the total volume of spray to be delivered to a tree crown or on a ground area basis. However, given the hill-like shape of the deposit distribution, the dose that a tree crown receives, specified either as the total volume or as volume per unit crown area, will be quite dependent on the size of the crown relative to the width of the deposit distribution (fig. 7). Assuming accurate targeting and that the tree crown sizes are known, deriving calibration curves like this for any spot spraying configuration allows easy adjustment of the total spray released to ensure that the target crown receives the required dose. For example, with the current configuration, the amount of spray received by a 2.0 diameter crown would be about $0.06 \mathrm{~L}$ (or equivalent to $190 \mathrm{~L} \mathrm{ha}^{-1}$ ). If a crown of this size only required $0.03 \mathrm{~L}$, the spraying duration could be halved.

Another way of expressing this information is to use equation 5 to define the deposition area $(A)$ receiving deposition levels greater than a specified threshold $\left(D_{t}\right)$. For example, with no significant difference among treatments $(\mathrm{p}=$ 0.39 ), an average area of $7.2 \mathrm{~m}^{2}$ received a dose of at least $50 \mathrm{~L} \mathrm{ha}^{-1}$ irrespective of droplet size. With a circular spot, an area of $7.2 \mathrm{~m}^{2}$ is equivalent to a spot diameter of $3 \mathrm{~m}$. As long as the minimum dose that will achieve efficacy can be

Table 2. Parameter estimates for each flight and flight variables. The area of the distribution $(A)$ is calculated using equation 5 with a deposition threshold of $0.005 \mathrm{~L} \mathrm{~m}^{-2}$. All angles (wind direction, $\theta$, and $\phi$ ) are expressed in degrees clockwise from north.

\begin{tabular}{|c|c|c|c|c|c|c|c|c|c|c|c|c|c|c|}
\hline Treatment & Replicate & $\begin{array}{c}V \\
(\mathrm{~L})\end{array}$ & $\begin{array}{c}\mu_{x} \\
(\mathrm{~m})\end{array}$ & $\begin{array}{c}\mu_{y} \\
(\mathrm{~m})\end{array}$ & $\begin{array}{c}\sigma_{x} \\
(\mathrm{~m})\end{array}$ & $\begin{array}{c}\sigma_{y} \\
(\mathrm{~m})\end{array}$ & $\rho$ & $\begin{array}{c}A \\
\left(\mathrm{~m}^{2}\right)\end{array}$ & $\begin{array}{c}L \\
(\mathrm{~m})\end{array}$ & $\begin{array}{c}\theta \\
\left(^{\circ}\right)\end{array}$ & $R$ & $\begin{array}{c}\phi \\
\left(^{\circ}\right)\end{array}$ & $\begin{array}{l}\text { Wind } \\
\text { Speed } \\
\left(\mathrm{m} \mathrm{s}^{-1}\right)\end{array}$ & $\begin{array}{c}\text { Wind } \\
\text { Direction } \\
\left({ }^{\circ}\right)\end{array}$ \\
\hline 1 & 1 & 0.102 & -0.38 & -1.42 & 1.08 & 0.84 & -0.288 & 7.20 & 1.47 & 195 & 0.68 & 115 & 0.7 & 23 \\
\hline 1 & 2 & 0.094 & -1.05 & -1.14 & 0.91 & 0.88 & -0.442 & 6.41 & 1.55 & 223 & 0.62 & 132 & 1.3 & 34 \\
\hline 1 & 3 & 0.110 & -0.55 & -0.62 & 0.92 & 0.92 & -0.100 & 7.54 & 0.83 & 222 & 0.90 & 134 & 2.1 & 55 \\
\hline 1 & 4 & 0.092 & -0.72 & -1.40 & 0.94 & 0.82 & -0.391 & 6.32 & 1.58 & 207 & 0.65 & 125 & 1.9 & 51 \\
\hline 2 & 1 & - & - & 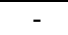 & - & 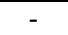 & 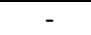 & - & - & - & - & - & - & 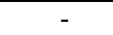 \\
\hline 2 & 2 & 0.118 & -1.21 & 0.28 & 0.78 & 1.02 & 0.355 & 7.59 & 1.24 & 283 & 0.63 & 26 & 1.2 & 123 \\
\hline 2 & 3 & 0.109 & -0.58 & 0.37 & 0.79 & 0.88 & 0.054 & 6.99 & 0.69 & 302 & 0.89 & 14 & 0.9 & 118 \\
\hline 2 & 4 & 0.115 & -0.85 & 0.34 & 0.81 & 0.95 & 0.123 & 7.51 & 0.91 & 292 & 0.82 & 20 & 0.8 & 117 \\
\hline 3 & 1 & 0.107 & -0.26 & -0.83 & 0.86 & 0.86 & -0.100 & 7.06 & 0.87 & 197 & 0.90 & 135 & 1.0 & 53 \\
\hline 3 & 2 & 0.104 & -0.57 & -0.78 & 0.91 & 0.79 & -0.195 & 6.87 & 0.97 & 216 & 0.78 & 117 & 1.2 & 77 \\
\hline 3 & 3 & 0.124 & -0.55 & -0.01 & 0.88 & 0.92 & -0.046 & 8.04 & 0.55 & 269 & 0.93 & 159 & 1.7 & 67 \\
\hline 3 & 4 & 0.113 & -0.44 & -0.63 & 0.94 & 0.76 & 0.033 & 7.23 & 0.77 & 215 & 0.81 & 86 & 0.5 & 33 \\
\hline
\end{tabular}


(a)

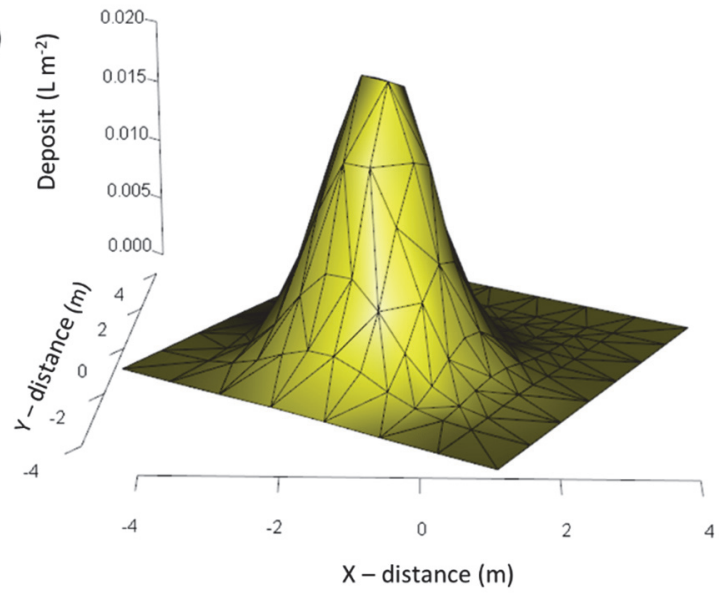

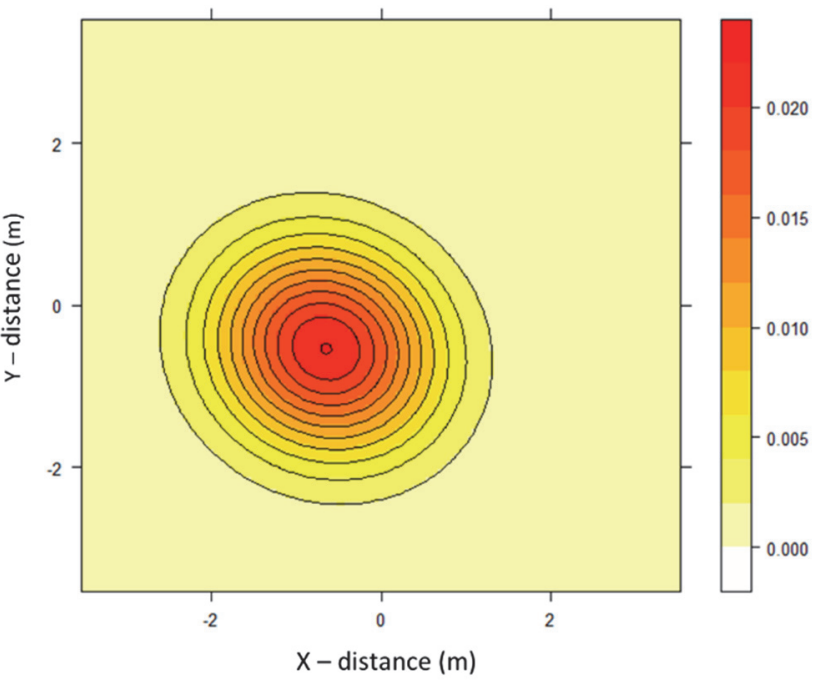

Figure 6. Spot deposit pattern from XAG P20 averaged over trial conditions and presented (a) in three dimensions and (b) as a contour plot.

defined, an effective treatment area can be estimated. For example, with a dose threshold of $30 \mathrm{~L} \mathrm{ha}^{-1}$, the effective treatment area is $9.5 \mathrm{~m}^{2}$, equivalent to a circular spot diameter of $3.5 \mathrm{~m}$. This approach is not the same as shown in figure 7, which is based on the overall average dose received by the crown rather than a distinct dose threshold at the crown edge. For example, an average dose of $50 \mathrm{~L} \mathrm{ha}^{-1}$ is equivalent to a crown diameter of about $5.0 \mathrm{~m}$ (fig. 7).

\section{TOTAL Deposition}

Averaging across all replicated flights, the calculated total spray volume deposited $(V)$ was $0.11 \mathrm{~L}$, with no significant differences among treatments $(p=0.07)$. The nominal volume applied, based on the nominal flow rate and the observed duration of spraying for each spot, averaged $0.17 \mathrm{~L}$. This result suggests that an average of only $65 \%$ of the applied spray was deposited on the grid. However, with uncertainty over the precise amount applied, it is not appropriate to conclude that $\sim 35 \%$ was lost to spray drift, especially with the relatively large droplets used. A more likely explanation is that the actual amount applied was lower than estimated, e.g., there could be a lag between the emergence of spray droplets and the system reaching the target flow rate. With a relatively short spraying duration (about 8 or $9 \mathrm{~s}$ ), a lag phase could represent a significant error in terms of total amount of spray released. It is clear that protocols for future work with UAV spraying systems that do not include a recording and calibrated flowmeter, as in this case, should require some other form of spray output measurement (e.g., weight before and after treatment application.

\section{TARGETING EFFICIENCY}

An effective spot application system must be well calibrated to deliver the correct dose to the target tree, and it must also be accurate, with the deposit distribution ideally centered on the middle of the tree crown. Based on the deposit distributions derived from the sampling grid, the distance $(L)$ from the deposition center to the plot center (the point over which the spot application was centered) ranged from 0.35 to $1.58 \mathrm{~m}$ (average of $1.04 \mathrm{~m}$ ). The upper end of this spot displacement range is significant in the context of the ability to deliver a specified dose to a target plant with a crown diameter of $1 \mathrm{~m}$ or more, or a ground area of similar dimension. As the target size increases, an offset of up to $1.58 \mathrm{~m}$ for the center of the deposit distribution will become less important, unless uniform herbicide coverage is essential for efficacy. However, with smaller crown diameters or ground target areas, an offset at of $1.5 \mathrm{~m}$ could mean a significant dose reduction. GPS data from the UAV and video

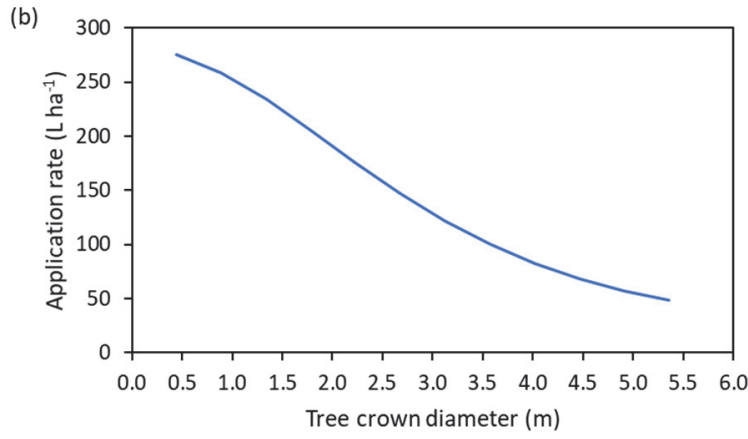

Figure 7. Amount of spray a tree crown receives can be specified in terms of (a) total volume or (b) volume per unit crown area. 
observations taken from directly above a subset of applications indicated that the offset in the position of the center of the deposit distribution was not related to the actual position of the UAV.

There was some evidence that $L$ was greater for the small droplet treatment $(p=0.053)$, with a mean displacement of $1.4 \mathrm{~m}$. The angle $(\theta)$ from the center of the distribution to the plot center was closely related to the wind direction (fig. 8), indicating that the center of mass for the deposit distribution moved downwind. While it also would be expected that $L$ would be positively correlated with measured wind speed, there was no evidence of this. Possible reasons for the lack of observed correlation between $L$ and wind speed include the relatively low wind speeds during the spray applications, possible differences in instantaneous wind speeds measured at the meteorological mast and the actual speed over the plots during spraying (the separation of the tower from the plots ranged from about 20 to $60 \mathrm{~m}$ ), and the fact that during several of the spray applications the wind speed was close to or below the lower sensitivity range of the anemometer used.

\section{DEPOSITION ON ARTIFICIAL TREES}

The preceding discussion relates to displacement of the deposit distribution measured at ground level and indicates displacement of the spot pattern from its point of origin. However, any tree canopy will be closer to that point of origin, and any displacement effects will be reduced. The model fitted to the ground-level deposition data did not predict deposition on the tree plates $\left(\mathrm{R}^{2}=0.04\right)$ even with linear adjustment to account for the offset between the point of release and deposition on the ground. However, an ANOVA testing spray deposition on tree plates at 1 and $2 \mathrm{~m}$ above ground, and on equivalently positioned ground plates, showed a consistent pattern of increasing deposition with height above ground (fig. 9). While there was no statistically significant effect of droplet size class on the proportion of plates receiving spray doses greater than any of the threshold values tested, i.e., 25, 50, and $100 \mathrm{~L} \mathrm{ha}^{-1}$ (ANOVA p-values ranged from 0.064 to 0.164 ), there were consistent trends (fig. 10). If the proportion of plates exceeding the threshold dose is termed the targeting efficiency, then the trend was for targeting efficiency to increase as droplet size increased,

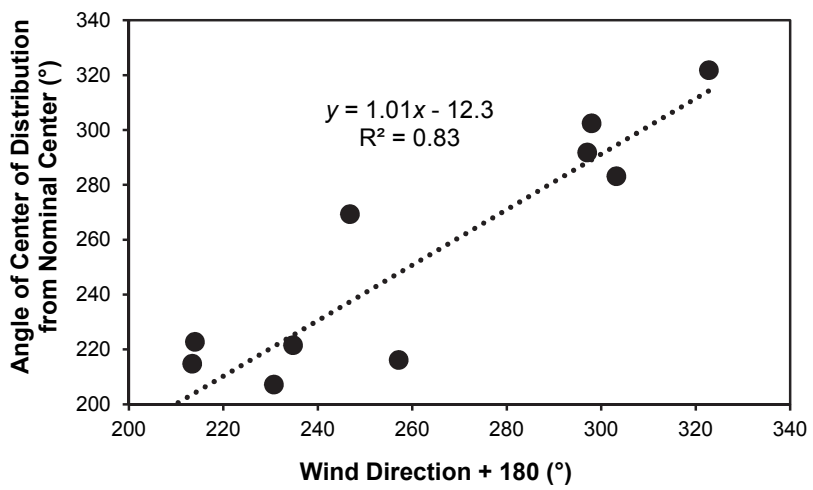

Figure 8. Relationship between the angle of the center of the spray distribution from the plot centFer $(\theta)$ and wind direction.

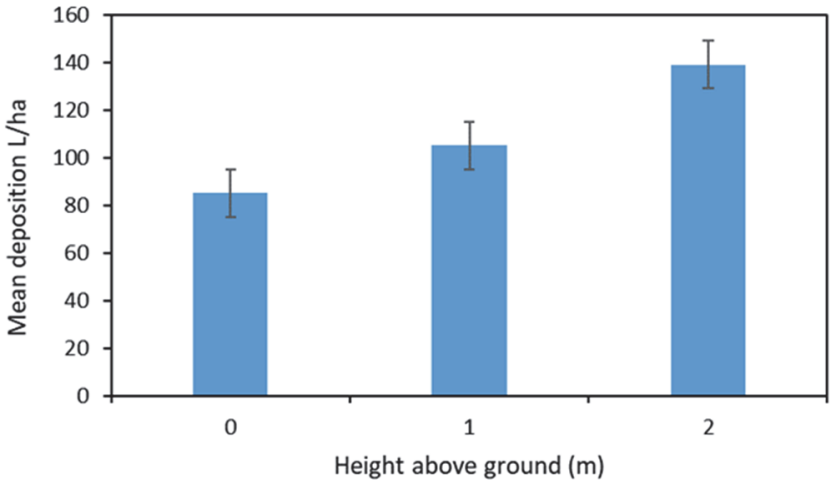

Figure 9. Mean deposition on artificial trees with plates at 1 and $2 \mathbf{m}$ heights compared with equivalently positioned plates at ground level. Standard errors are shown on each bar.

independent of dose threshold. As the dose threshold or sampling width (fig. 10a versus fig. 10b) decreased, the targeting efficiency also increased.

Overall, these results indicate good targeting efficiency from the XAG P20 and imply that replicating these conditions while spot spraying actual tree crowns would result in a high proportion $(>60 \%)$ of the tree crown receiving a dose of greater than $100 \mathrm{~L} \mathrm{ha}^{-1}$ (about two-thirds of the application rate) with droplet size classes of $430 \mu \mathrm{m}$ or higher.

\section{SAMPLING EFFICIENCY}

Using data restricted to plates spaced at $1 \mathrm{~m}$, the parameter estimates for the bivariate normal distribution function were comparable to those obtained using the full design, with the exception of estimates of $\phi$ (table 3). Distributions fitted using plates positioned along the two diagonals and a cross centered at the central point (table 3 ) also produced parameter estimates that were similar to those from the analysis based on the full dataset. However, if the peak of the distribution were to move further from the center at higher wind speeds than experienced during this study, and/or with smaller droplet sizes, there is a risk that the cross-diagonal approach would produce more biased results with its lower sampling density with distance from the grid center.

\section{Conclusions}

This study presents an effective methodology for quantifying and analyzing the two-dimensional deposit pattern from a UAV configured for individual plant spot spraying. A bivariate normal distribution provided a good fit to the observed pattern for all treatments and operating conditions. Results also indicated that reducing the sampling grid density for measuring ground deposition from 0.5 to $1 \mathrm{~m}$ spacing would not substantively change the parameter values but would significantly reduce the sampling effort. While the cross-diagonal spatial arrangement of the sampling grid looked favorable, there is a question as to its effectiveness in situations where the spot displacement is greater than observed in this study. 

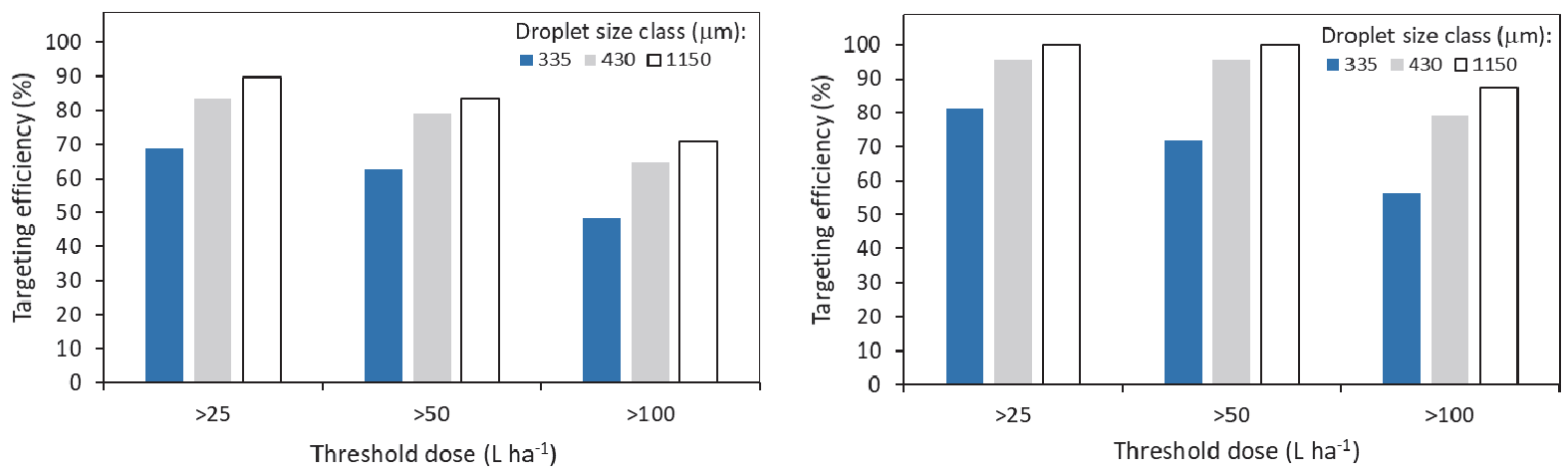

Figure 10. Effect of droplet size on targeting efficiency, i.e., the proportion of plates in an artificial tree receiving a dose above the designated threshold, based on (a) the whole tree (sampling width of $2 \mathrm{~m}$ ) and (b) inner samples only (sampling width of $1 \mathrm{~m}$ ).

The center of mass of the deposit distribution was displaced in a downwind direction, and the greatest displacement was observed with the smaller droplet size class. The degree of downwind displacement could not be correlated with wind speed. The most likely reasons for this apparent lack of relationship between displacement distance and wind speed are (1) the relatively low wind speeds and wind speed range experienced during the experiment, (2) the fact that for many of the spray applications the wind speed was close to the lower sensitivity range of the anemometer used, and (3) the horizontal distance $(\sim 20$ to $60 \mathrm{~m}$ ) between the wind speed measured at the meteorological tower and at the point of spray application.

Despite the offset in the center of the ground distribution pattern, the actual spray coverage on an artificial tree target of 1 or $2 \mathrm{~m}$ diameter was consistent across the range of droplet sizes and operating conditions tested. Nevertheless, it is hypothesized that targeting could be further improved if the UAV was slightly offset in an upwind direction and, conceptually, the degree of this displacement would increase as wind speed increased. To test this hypothesis, more deposit distribution data are required for a wider range of wind speeds, along with measurement of wind speed and direction closer to the point of spray application. Ideally, real-time measurement of wind speed would be taken on the UAV. While there would be complications in achieving direct measurement of wind speed on a UAV due to wake interference with ambient airflow, recent work has shown the potential for deriving actual wind speed and direction by inference from the aircraft tilt angle and the thrust required to maintain a steady velocity (Moyano Cano, 2013; Agrawal and Shrivastav, 2015; Palomaki et al., 2017; Sarghini and De Vivo, 2017; Wang et al., 2018). Developing and validating

Table 3. Estimates of distributional parameters based on reduced sampling designs. The full dataset uses a 149-plate design with plates at $0.5 \mathrm{~m}$ spacing. The three reduced designs are a 64-collector design with $1 \mathrm{~m}$ spacing, a 36-plate design with $1.5 \mathrm{~m}$ spacing, and a 45-plate design using the central cross and diagonals of the full design.

$\mathrm{R}^{2}$ values for comparisons of distribution parameters

for full dataset and three reduced sampling designs

\begin{tabular}{cccc} 
& & & \\
\cline { 2 - 4 } Parameter & $1 \mathrm{~m}$ Spacing & $1.5 \mathrm{~m}$ Spacing & Cross-Diagonal \\
\hline$V$ & 0.75 & 0.54 & 0.68 \\
$L$ & 0.99 & 0.94 & 0.99 \\
$\theta$ & 0.99 & 0.95 & 0.99 \\
$R$ & 0.73 & 0.02 & 0.74 \\
$\phi$ & 0.34 & 0.84 & 0.67 \\
\hline
\end{tabular}

this methodology for different UAVs and operating scenarios would be highly beneficial for many applications.

The targeting efficiency of the XAG P20 aircraft was excellent, as confirmed by observations and overhead video recordings. While the estimate of spray recovery was much lower than expected for such large droplet size classes, the uncertainty in the actual amount of spray released means that this part of the study should be repeated before drawing conclusions about spray application efficiency. Despite shortcomings in the measurement methods, it was clear that the droplet sizes produced by the $\mathrm{P} 20$ were also much larger than expected, indicating that further work is needed on droplet size calibration for this system.

\section{ACKNOWLEDGEMENTS}

Funding for this work was provided by the New Zealand MBIE Endeavour Fund (Contract No. C09X1611, "Winning against Wildings") and New Zealand Forest Growers Research. XAG provided the P20 aircraft and contributed time and expertise in undertaking the flying and spray application. HeliResources Ltd. provided the venue for the field trial. Scion technical contributors included Vanessa Cotterill, Liam Wright, Carolina Gous, and John Meredith.

\section{REFERENCES}

Agrawal, K., \& Shrivastav, P. (2015). Multi-rotors: A revolution in unmanned aerial vehicle. Intl. J. Sci. Res., 4(11), 1800-1804. https://doi.org/10.21275/v4i11.NOV151540

Davenhill, N. A., Vanner, A. L., \& Richardson, B. (1991). Spot weed control - Granules or sprays? In M. I. Menzies, G. E. Parrott, \& L. J. Whitehouse (Eds.), Proc. IUFRO Conf. Efficiency of Stand Establishment Operations (pp. 250-253). Vienna, Austria: International Union of Forest Research Organizations.

Faiçal, B. S., Costa, F. G., Pessin, G., Ueyama, J., Freitas, H., Colombo, A., ... Braun, T. (2014). The use of unmanned aerial vehicles and wireless sensor networks for spraying pesticides. $J$. Syst. Architec., 60(4), 393-404. https://doi.org/10.1016/j.sysarc.2014.01.004

Giles, D. K., \& Billing, R. C. (2015). Deployment and performance of a UAV for crop spraying. Chem. Eng. Trans., 44, 307-312. https://doi.org/10.3303/CET1544052 
Gous, S., Raal, P., \& Watt, M. S. (2014). Aerial spot treatment using an oil carrier to apply ester-based herbicides for control of Pinus contorta and P. nigra in New Zealand. New Zealand J. Forestry Sci., 44(1), 23. https://doi.org/10.1186/s40490-0140023-6

Huang, Y., Hoffmann, W. C., Lan, Y., Wu, W., \& Fritz, B. K. (2009). Development of a spray system for an unmanned aerial vehicle platform. Appl. Eng. Agric., 25(6), 803-809. https://doi.org/10.13031/2013.29229

Ledgard, N. (2001). The spread of lodgepole pine (Pinus contorta, Dougl.) in New Zealand. Forest Ecol. Mgmt., 141(1-2), 43-57. https://doi.org/10.1016/S0378-1127(00)00488-6

Matthews, G. (2008). Pesticide application methods. Hoboken, NJ: John Wiley \& Sons.

Moyano Cano, J. (2013). Quadrotor UAV for wind profile characterization. MS thesis, industrial engineering. Madrid, Spain: Universidad Carlos III de Madrid, Departamento de Informática. Retrieved from http://hdl.handle.net/10016/18105

Palomaki, R. T., Rose, N. T., van den Bossche, M., Sherman, T. J., \& De Wekker, S. F. J. (2017). Wind estimation in the lower atmosphere using multirotor aircraft. J. Atmos. Oceanic Tech., 34(5), 1183-1191. https://doi.org/10.1175/JTECH-D-16-0177.1

Parkin, C. S., \& Wyatt, J. C. (1982). The determination of flightlane separations for the aerial application of herbicides. Crop Prot., 1(3), 309-321. https://doi.org/10.1016/02612194(82)90006-0

Richardson, B., \& Thistle, H. W. (2006). Measured and predicted aerial spray interception by a young Pinus radiata canopy. Trans. ASABE, 49(1), 15-23. https://doi.org/10.13031/2013.20230

Richardson, B., Kimberley, M. O., \& Schou, W. C. (2004). Defining acceptable levels of herbicide deposit variation from aerial spraying. Appl. Eng. Agric., 20(3), 259-267. https://doi.org/10.13031/2013.16059

Richardson, B., Kimberley, M. O., Rolando, C. A., Coker, G. W., \& Gous, S. (2019). Optimizing spot weed control regimes for Pinus radiata plantations. Canadian J. Forest Res., 49(7), 759766. https://doi.org/10.1139/cjfr-2018-0411

Richardson, B., Ray, J., \& Vanner, A. L. (1989). Evaluation of techniques to measure aerial spray deposition. New Zealand Plant Prot., 42, 132-136. https://doi.org/10.30843/nzpp.1989.42.10972
Sarghini, F., \& De Vivo, A. (2017). Interference analysis of a heavy-lift multirotor drone flow field and transported spraying system. Chem. Eng. Trans., 58, 631-636. https://doi.org/10.3303/CET1758106

SAS. (1987). SAS/STAT guide for personal computers. Cary, NC: SAS Institute, Inc.

Strand, T. M., Rolando, C. A., Richardson, B., Gous, S., Bader, M. K., \& Hammond, D. (2014). An aerial spot-spraying technique: A pilot study to test a method for pest eradication in urban environments. SpringerPlus, 3(1), article 750. https://doi.org/10.1186/2193-1801-3-750

Sundaram, A., Sundaram, K. M. S., \& Leung, J. W. (1991). Droplet spreading and penetration of non-aqueous pesticide formulations and spray diluents in Kromekote cards. Trans. ASAE, 34(5), 1941-1951. https://doi.org/10.13031/2013.31820

Tang, Q., Zhang, R. R., Chen, L. P., Xu, M., Yi, T. C., \& Zhang, B. (2017). Droplets movement and deposition of an eight-rotor agricultural UAV in downwash flow field. Intl. J. Agric. Biol. Eng., 10(3), 47-56. https://doi.org/10.3965/j.ijabe.20171003.3075

Wang, G., Lan, Y., Qi, H., Chen, P., Hewitt, A., \& Han, Y. (2019). Field evaluation of an unmanned aerial vehicle (UAV) sprayer: Effect of spray volume on deposition and the control of pests and disease in wheat. Pest Mgmt. Sci., 75(6), 1546-1555. https://doi.org/10.1002/ps.5321

Wang, J. Y., Luo, B., Zeng, M., \& Meng, Q. H. (2018). A wind estimation method with an unmanned rotorcraft for environmental monitoring tasks. Sensors (Switzerland), 18(12), 4504. https://doi.org/10.3390/s18124504

Wang, S. L., Song, J. L., He, X. K., Song, L., Wang, X. N., Wang, C. L., ... Ling, Y. (2017). Performance evaluation of four typical unmanned aerial vehicles used for pesticide application in China. Intl. J. Agric. Biol. Eng., 10(4), 22-31. https://doi.org/10.25165/j.ijabe.20171004.3219

Xue, X. Y., Tu, K., Qin, W. C., Lan, Y. B., \& Zhang, H. H. (2014). Drift and deposition of ultra-low altitude and low volume application in paddy field. Intl. J. Agric. Biol. Eng., 7(4), 23-28. https://doi.org/10.3965/j.ijabe.20140704.003 